\title{
Evaluation of Food Hygiene Knowledge Attitudes and Practices of Food Handlers in Food Businesses in Accra, Ghana
}

\author{
George Amponsah Annor*, Ekua Anamoaba Baiden \\ Department of Nutrition and Food Science, University of Ghana, Legon, Accra. \\ Email: "gannor@ug.edu.gh, georgeannor@yahoo.com
}

Received July 22 ${ }^{\text {nd }}, 2011$; revised September $1^{\text {st }}$, 2011; accepted September $8^{\text {th }}, 2011$.

\begin{abstract}
Food handlers have a prime role to play in food businesses, and that is to guarantee that meals served are hygienic for consumption. Conscious or inadvertent contamination of such food places consumers at risk of suffering from foodborne illnesses. For this reason the study was carried out to document the food hygiene knowledge, attitudes and practices of some food handlers, in food businesses in Accra, Ghana and also to determine the microbiological load of the foods sold by the food businesses. The study targeted food handlers in the hotel industry. The study involved a field survey, followed by a laboratory assessment of microbiological status of food samples obtained from the sampled hotels. Cross tabulations and chi-squared tests (5\% significance level) as well as frequency distributions were used to analyze the data obtained from the field survey. Data obtained from the laboratory assessment were also compared to standard values of microbiological counts. Majority of respondents were between the ages of 30 - 40 years (42.9\%) with tertiary or post secondary education. Food hygiene knowledge and attitudes were satisfactory, however its practice was challenging. Gender, age and educational level of respondents did not influence their food hygiene practices. Microbial counts of all food samples was generally high ranging from $1.2 \times 10^{5} \mathrm{CFU} / \mathrm{g}$ to $1.1 \times 10^{8} \mathrm{CFU} / \mathrm{g}$. The total coliform counts of foods ranged from $1.0 \times 10^{4} \mathrm{CFU} / \mathrm{g}$ to $5.0 \times 10^{6} \mathrm{CFU} / \mathrm{g}$, and these were obtained from three out of the five hotel kitchens sampled. The study concluded that, the food hygiene knowledge and attitudes of the food handlers did not result in efficient food hygiene practices.
\end{abstract}

Keywords: Knowledge, Attitudes, Practices, Food Handlers, Ghana

\section{Introduction}

Food businesses have become widespread in recent times, in response to the changing lifestyle and food consumption of people. They offer convenience and ease of access to food to busy individuals, who are unable to prepare their own meals regularly at home. In large scale cooking, food passes through many hands, thereby increasing the chances of food contamination due to improper handling. Deliberate or accidental contamination of food during large production might endanger the health of consumers, and have very expensive repercussions on a country, as such outbreaks feature prominently in national statistics [1,2]. Food-borne disease outbreaks that have been reported in the United States for instance, with the assertion of mishandling, have implicated food from commercial or institutional establishments (79\%) and $20 \%$ from homes. An estimated 25\% of these reports could have been avoided by safe food handling practices [3]. Successive food scares and mounting incidences of food poisoning, such as cases due to E.coli and Campylobacter have placed food safety as a priority across European governments. In considering the actual level of food-borne illnesses, there is difficulty in establishing the exact numbers of incidents, as cases of illnesses are significantly underreported [4]. Attempts to approximate the number of incidences that originate from the home make it impossible to obtain a true estimate of food-borne illnesses. In the case of the Republic of Ireland, $17 \%$ of food-borne outbreaks were linked to home consumption [5]. It has been however suggest that, the actual proportion of incidents originating in the home are likely to be much higher than reported [6]. Knowledge of food risks assessed on the Irish populace has concluded on certain issues including the fact that, the characteristics of individuals influence their level of understanding. For 
instance experts from the island of Ireland have linked educational level and age, as factors that affect the understanding of food risk issues [7].

Numerous studies conducted in Ghana concerning various aspects of food hygiene over the past decade, have revealed poor food hygiene knowledge and attitudes of street food vendors, with personal hygiene least observed by the least educated [8-10]. There is strong statistical evidence that $70 \%$ of all bacterial food poisoning is caused by caterers. This is greater than occurrences reported from any other food sector. Most of these food poison outbreaks are due to the inadequate time and temperature control of food, whereas the remaining thirty percent are as a result of cross contamination [11]. In Turkey, many issues that impose risk on food safety, and these are due to industrialization and mass production, fast food consumption, street vendors and growing international trade and tourism were identified [7]. A similar account could be cited for Ghana as the likely causes of food safety problems. This study therefore sought to evaluate the current activities of food handlers in the hotel industry in the country with respect to food safety.

\section{Methodology}

\subsection{Study Design}

The study involved a field survey and a laboratory assessment of the microbiological status of food samples collected from the sample hotels. In the field survey, pre-tested semi-structured questionnaires were used to interview food handlers in the sampled food businesses to evaluate their knowledge, attitudes and practices of food hygiene. The laboratory analyses involved collection of food samples from the hotels, and subsequent determination of their microbial counts in the laboratory to assess their immediate microbiological quality.

\subsection{Sampling}

The population of subjects for this study was food handlers in the kitchens of hotels, registered under the Ghana Hotels Association in Accra, Ghana. The software Epi info (version 6, Centre for Disease Control and Prevention (CDC), Atlanta, Georgia, USA) was used to compute the sample size, based on the total number of registered hotel establishments to the association in Accra. Indices used to compute the sample size were: confidence level of ninety five percent (95\%), an error margin of $0.05 \%$, a power default of eighty percent ( $80 \%$ ) and a fifty percent $(50 \%)$ frequency of a 50-50 chance of appropriate knowledge, attitude and practice of food hygiene by food handlers. The computed sample size was a minimum of three (3) out of a population of thirty three
(33) hotels. Five member hotels and one non-member hotel were eventually chosen for the study. The number of interviewed food handlers in each hotel kitchen was based on convenience. Due to varying numbers of food handlers in each hotel kitchen, ten percent (10\%) of the total number of food handlers observed in each kitchen were randomly selected and interviewed. Forty two questionnaires were distributed to respondents from all six hotels sampled. The questionnaires were used to collect information on demographics, food hygiene knowledge and practice, food handling and health problems, food hygiene attitudes and finally knowledge of food borne bacterial pathogens.

\subsection{Food Sampling}

One meal of the meals served in each hotel was randomly collected for laboratory analyses in a week. Foods served to customers were aseptically sampled at the points of serving. All components of the meals obtained were analyzed. The meals were consisted of rice (which was boiled or fried; thus as plain white rice, jollof rice or fried rice), meat or poultry (meat was boiled and then added to lightly fried vegetable sauce and then poultry was either fried or grilled) and tomato stew/sauce. Shito (a popular Ghanaian chili sauce which includes blended pepper, fried with oil and spices) was also encountered.

\subsection{Identification of Microorganisms}

Food samples were prepared, cultured in their respective media and incubated. The microorganisms were identified and their counts were compared to standard values of microbiological counts [12,13].

\subsection{Statistical Analysis}

Cross tabulations and chi-squared tests (5\% signifycance level) were used to determine the influence of gender, age, educational level, bacterial knowledge and place of work on food storage and safety, hygiene and cleaning, food preparation as well as food handling and health problems. Scores for a selected test category (thus food hygiene knowledge and practice) were calculated by assigning correct responses. Frequency distributions were used to compare results among the respondents from the different hotels. The SPSS 16.0 (SPSS Incorporated, Atlanta, Illinois, USA) statistical package and Microsoft Excel were used for all analyses.

\section{Results and Discussion}

\subsection{Characteristics of Respondents}

Fifty percent of the respondents were males and fifty percent were females. Most studies report a higher proportion of 
females [14]. Majority of the respondents were either under thirty years or between the ages of thirty and forty years. All the food handlers interviewed had some form of education and/or training. About $40.5 \%$ of the respondents had obtained tertiary or post secondary education. The number of years spent in the food business was varied. Respondents were found to have worked in the food business for an average of 9.4 years (SD $=2.6$; median $=2$ years and mode 1 and 5 years).

\subsection{Food Hygiene Attitudes Exhibited by Respondents}

Findings for the food hygiene attitude test category is summarized and displayed in Table 1. Among the six hotels sampled, $40.5 \%$ respondents of the population reported that the head chef was responsible for inspection of suppliers. The frequency of inspection of suppliers was reported to be done every time there was a delivery by $61.9 \%$ of respondents.

Table 1. Food hygiene attitudes.

\begin{tabular}{|c|c|}
\hline Variable & Frequency (\%) \\
\hline \multicolumn{2}{|c|}{ Responsible individuals who inspect suppliers } \\
\hline Head chef & $17(40.5)$ \\
\hline Catering manager & $2(4.8)$ \\
\hline Health board & $3(7.1)$ \\
\hline Store keeper & $15(35.7)$ \\
\hline Other & $5(11.9)$ \\
\hline Total & $42(100.0)$ \\
\hline \multicolumn{2}{|c|}{ Frequency of inspection of suppliers } \\
\hline Spot checks & $4(9.5)$ \\
\hline Every time there is a delivery & $26(61.9)$ \\
\hline Once a day & $5(11.9)$ \\
\hline Once a week & $6(14.3)$ \\
\hline Once a month & $1(2.4)$ \\
\hline Total & $42(100.0)$ \\
\hline \multicolumn{2}{|c|}{ Query about safety of consumption of refrigerated food up to 2 or 3 days } \\
\hline Yes & $14(33.3)$ \\
\hline No & $28(66.7)$ \\
\hline Total & $42(100.0)$ \\
\hline \multicolumn{2}{|c|}{ Query about necessity of thorough hand washing after visiting the toilet } \\
\hline Yes & $42(100.0)$ \\
\hline No & $0(0.0)$ \\
\hline Total & $42(100.0)$ \\
\hline \multicolumn{2}{|c|}{ Temperature at which uneaten foods are reheated } \\
\hline Above $60^{\circ} \mathrm{C}$ & 30 (71.4) \\
\hline Below $60^{\circ} \mathrm{C}$ & $23(23.8)$ \\
\hline Not applicable & $2(4.8)$ \\
\hline Total & $42(100.0)$ \\
\hline
\end{tabular}


The query about the safety of consumption of refrigerated food up to two or three days yielded 33.3\% of respondents answering 'yes', thus implying safety of consumption of the food and $66.7 \%$ of respondents reporting that it was not safe to consume such food. A similar query yielded $79 \%$ of respondents obtaining the correct answer [4]. Majority of respondents interviewed (71.4\%) reported the temperature at which uneaten foods must be reheated, to be above sixty degrees Celsius, whereas $23.8 \%$ and $4.8 \%$ of respondents either chose below sixty degrees Celsius or thought that the temperature given was not applicable.

\subsection{Knowledge and Practice of Food Hygiene}

Gender was found to be statistically independent of the food hygiene knowledge and practice of the respondents, except for their methods of defrosting meat or poultry, where males chose to thaw in cooling units rather than risk thawing at room temperature $\left(\mathrm{X}^{2}=11.821 ; \mathrm{P}=\right.$ 0.008). Majority of the males (85.7\%) chose to defrost meat or poultry in a refrigerator/ cold room, in the defrost cycle in a microwave, or in a basin of cold water. Majority of the females $(61.9 \%)$ also chose to leave the meat/poultry out at room temperature to defrost it. Although thawing in the refrigerator is not entirely necessary for food safety, as long as the time-temperature is respected [15]. Food must never be defrosted at room temperature [16]. Keeping meat and poultry cold while it is defrosting is essential to prevent the growth of harmful bacteria. There is greater danger of bacterial growth and food spoilage for food thawed at room temperature, hence the best way to safely thaw meat and poultry is in the refrigerator. The microwave can also be used to defrost meat more rapidly. Food may also be thawed in cold water in a sink or container and this must be clean [16].

Age of the respondents was found not to influence the knowledge and practice of food hygiene of the respondents. However, the significance of age on the measures used by respondents to ensure that, knives used for raw foods are not afterward used on foods that would not be cooked was proven. $\left(X^{2}=27.606 ; P=0.001\right)$. Ready-toeat foods must never be prepared using a chopping board or knife, that have been used to prepare raw meat, unless they have been washed thoroughly first [17].

The educational level of respondents did not influence respondents' knowledge and practice of food hygiene. The place of work of respondents was found to signifycantly influence knowledge and practice on food storage and safety, food preparation and food handling and health problems but not their knowledge and practice on hygiene and cleaning.

Concerning responses for food storage, food handlers from the different hotels varied in their response to the appropriate temperature for the refrigerator $\left(X^{2}=32.717\right.$; $\mathrm{P}=0.005$ ). Majority of respondent from GOTH hotel (80.0\%) and HOET hotel (66.7\%) knew the correct temperature range of $1^{\circ} \mathrm{C}-5^{\circ} \mathrm{C}$ for the refrigerator. From HOTA hotel, FAHT hotel, and FEST hotel, 50.0\%, $18.2 \%$ and $20.0 \%$ of their respondents respectively, chose the correct temperature range for the refrigerator. Of the forty two food handlers interviewed, only $42.9 \%$ knew that $1^{\circ} \mathrm{C}-5^{\circ} \mathrm{C}$ was the correct temperature for the refrigerator.

Majority of respondents from GOTH (80.0\%), HOTA (100.0\%) and FEST (60.0\%) agreed that, when food became mouldy or had a bad smell, then they will be certain, it contains bacteria causing food borne disease. Foods contaminated with disease causing organisms are considered by some microbiologists as spoilt [18]. This type of spoilage is distinguished from organoleptic spoilage in which flavour, odour and changes in appearance are evident. In the majority of cases the food involved shows no sign of any symptoms that would enable a consumer to determine, whether the food is acceptable and would not normally be considered as spoilt.

On the issue of storage position of a vegetable salad when a large piece of meat is stored on the middle rack, majority of the respondents from all the hotels knew they were to place the salad on top, to prevent contamination from the drip of the meat. This result corroborates with a study where majority (92\%) of respondents reported correctly separating raw meat from other foods during storage [19]. A total of $23.8 \%$ of the forty two respondents from this study reported that, they would place the salad next to the meat, while $4.8 \%$ were not certain where to place the salad. This represented the responses by the minority of respondents from the hotels involved in the study. Similar result, thus $10 \%$ of their respondents did not effectively separate such food items. This according to the authors is disturbing.

\subsection{Food Handling and Health Problems}

Food handling and health problems were not influenced by gender, age, educational level and bacterial knowledge. On the other hand, the place of work of respondents appreciably influenced their responses to food handling and health problems. The knowledge of handling food when having diarrhoea $\left(X^{2}=18.847 ; P=0.042\right)$, and when having a raised temperature $\left(\mathrm{X}^{2}=19.326\right.$; $\mathrm{P}=$ $0.036)$ were influenced by the hotels in which respondents were working.

While $11.1 \%$ of respondents from HOET and $40.0 \%$ of respondents from MHOT hotel would handle food when having diarrhoea, all respondents from the other 
hotels would not. In another study, almost $5 \%$ of the workers reported working while sick with vomiting or diarrhea [20]. Food handling and preparation for sale must not be done by persons, if they have suffered from diarrhoea in the last two or three days [21]. If there is only one bout of diarrhoea and vomiting in a 24 hour period, and there is no fever, the person may resume food handling duties. With this they should have been reminded of the importance to hand washing, thus good hygiene practice. However if symptoms persists, the person must seek medical advice and can only return to work after the health workers advice to do so. For handling of food when having a raised temperature, $80.0 \%$ of respondents from MHOT hotel would handle food, while majority of respondents from each of the remaining five hotels would not.

Although the place of work, gender, educational level and bacterial knowledge did not influence the responses for food handling when coughing and wearing protective mask, majority of respondents (71.4\%) from the study said they would not handle food when coughing and wearing a protective mask. When a similar query was posed to food handlers in Slovenia in a study in another study, most respondents believed that, they should not handle food when coughing and wearing mouth masks. It is obvious that, the respondents do not fully understand individual hazards, their risks and methods of managing such hazards. This is so because, food handling is allowed if protective mask is worn. [14]. The Food and drugs board of Ghana has been mandated to ensure foods sold by food handlers are suitable and also safe for human consumption including proper handling of foods.

\subsection{Microbiological Counts in Foods Sold by Food Handlers}

There was a correlation between the services offered by the different hotels and the level of contamination of foods. Observations made on some of the premises of the sampled kitchens suggested their contribution to the food contamination. The microbial count from the hotel with the worst food hygiene checks, thus no head gears or gloves worn by food handlers, were the highest (maximum count of $1.1 \times 10^{8} \mathrm{CFU} / \mathrm{g}$ ) (Table 2), but were least at the hotel with the best observed food hygiene checks (food handlers seen in aprons, head gears, and gloves, as well as clean environment) (maximum count of $1.2 \times 10^{5}$ $\mathrm{CFU} / \mathrm{g}$ ). This observation suggests that when food hygiene checks are strictly followed, contamination could be reduced. The microbial counts of all food samples ranged from $1.2 \times 10^{5} \mathrm{CFU} / \mathrm{g}$ to $1.1 \times 10^{8} \mathrm{CFU} / \mathrm{g}$. Ranges of 105-6 CFU/g represents high counts, $10^{7}$ $\mathrm{CFU} / \mathrm{g}$ represents an index of spoilage and $10^{8} \mathrm{CFU/g}$ represents odour development [12]. The data suggests that food obtained contained high counts of microorganisms.

The presence of total coliforms, (which are indicative of insanitary practices) and Staphylococcus aureus were absent in food sampled from GOTH hotel. The determination of Staphylococcus aureus is very important for microbiological safety considerations, but not in itself an indication of a food safety hazard. This is because Staphylococcus aureus is a part of the normal micro flora of the skin of humans [21]. Staphylococcus aureus was identified in food sampled from the other four hotels. The count obtained for this microorganism for food sampled from HOTA, HOET, FAHT and MHOT hotels ranged between $9.0 \times 10^{4} \mathrm{CFU} / \mathrm{g}-2.0 \times 10^{6} \mathrm{CFU} / \mathrm{g}$. The number of cells required to secrete enough toxins to produce a Stapylococcal disease, is estimated to be about $5.0 \times 10^{6} / \mathrm{g}$ of the food ingested or higher [19]. Furthermore, an estimate of $30 \%-50 \%$ of the human populations is nasal and throat carriers of Staphylococcus aureus. The general role of hand washing in preventing disease is well known in the catering industry, and positive attitudes to hand washing among caterers have been reported in several other studies in Italy [22]. Positive hand washing among respondents was also reported in this study. Microbiological counts obtained in Table 2, and observational studies carried out suggest that, knowledge

Table 2. Microbial counts of food samples.

\begin{tabular}{|c|c|c|c|c|c|}
\hline HOTEL & PCA (CFU/g) & PDA (CFU/g) & VRBGA (CFU/g) & EMB (CFU/g) & BPA (CFU/g) \\
\hline HOTA & $2.5 \times 10^{6}$ & $6.0 \times 10^{5}$ & 0.0 & - & $2.0 \times 10^{6}$ \\
\hline GOTH & $1.2 \times 10^{5}$ & $1.0 \times 10^{4}$ & 0.0 & - & 0.0 \\
\hline HOET & $3.8 \times 10^{6}$ & $8.0 \times 10^{4}$ & $7.0 \times 10^{4}$ & - & $9.0 \times 10^{4}$ \\
\hline FAHT & $1.5 \times 10^{7}$ & $4.0 \times 10^{5}$ & $1.0 \times 10^{4}$ & $1.0 \times 10^{3}$ & $3.1 \times 10^{5}$ \\
\hline MHOT & $1.1 \times 10^{8}$ & $1.0 \times 10^{6}$ & $5.0 \times 10^{6}$ & $5.0 \times 10^{4}$ & $6.0 \times 10^{5}$ \\
\hline
\end{tabular}

KEY-HOTA, GOTH, HOET, FAHT and MHOT: Codes assigned to hotels. 
is not always put into practice [19]. This suggestion can be made because, thorough hand washing, if had been practiced by food handlers would have produced low microbial counts, especially of coliforms (E.coli which is indicative of faecal contamination) and Staphylococcus aureus.

From the results on Table 2, the total coliform counts of foods ranged from $1.0 \times 10^{4} \mathrm{CFU} / \mathrm{g}$ to $5.0 \times 10^{6} \mathrm{CFU} / \mathrm{g}$, and these were obtained from three out of the five hotel kitchens sampled. Foods considered wholesome for consumption must not have any coliforms (0 CFU/g) [13].

Of the three hotel kitchens from which coliforms were identified, the presence of E.coli was tested in foods from two them. E.coli was present in the foods at $1.0 \times 10^{3}$ $\mathrm{CFU} / \mathrm{g}$ and $5.0 \times 10^{4} \mathrm{CFU} / \mathrm{g}$. Their presence in the foods has a food-borne disease significance. This is because certain strains like E.coli O157: H7, are pathogenic and cause severe food poisoning. The dreadful health and food safety concern about this strain is the association between the Shiga-toxin-producing E.coli serotypes and haemolytic uremic syndrome (5\% to $10 \%$ of patients) and kidney failure (another 5\% of patients). About 50\% of patients have long-term renal dysfunction, with mortality of about 5\% [2]. The microbial counts obtained were however lower than that observed in some street foods in Accra [23].

\section{Conclusions and Recommendations}

Generally, it was observed that respondents had a satisfactory level of knowledge of food hygiene. Some of the respondents however had some lapses in their responses to queries on 'food hygiene knowledge and practices'. Test of knowledge on food handling and health problems on respondents proved that, the respondents did not fully understand individual hazards, their risks and methods of managing such hazards. It was observed from these queries that, knowledge was not always put into practice. Data obtained from the microbial analysis also suggested that, there was a risk of consumers being exposed to contaminated food. This was illustrated by the presence of coliforms (E.coli in food samples from two of the hotels) and Staphylococcus aureus in food from four out the five hotels (though their quantities were not high enough to cause Stapylococcal food borne disease). Though respondents were found to have satisfactory food hygiene attitudes, results of the microbial analysis proved that, it did not produce strict food hygiene practices. Strict food hygiene practices must therefore be followed by the food handlers, to prevent cross-contaminations of foods served to consumers. Mangers should also not only be content with their attainment of structural design requirement for hygiene practice, but develop tactics to motivate their food handlers to practice food hygiene.

\section{REFERENCES}

[1] M. Adams and Y. Motarjemi, "Basic Food Safety for Health Workers,” World Health Organization, Geneva, 1999, pp. 113-114.

[2] S. T. Omaye, "Food and Nutritional Toxicology," CRC Press LLC, Boca Raton, 2004, pp. 163-173.

[3] I. Haapala and C. Probart, "Food Safety Knowledge, Perceptions and Behaviours among Middle School Students," Journal of Nutrition Education Behaviour, Vol. 36, No. 2, 2004, pp. 71-76. doi:10.1016/S1499-4046(06)60136-X

[4] M. McCarthy, M Brennan, A. L. Kelly, C. Ritson, M. deBoer and N. Thompson, "Who Is at Risk and What Do They Know? Segmenting a Population on Their Food Safety Knowledge,” Journal of Food Quality and Preference, Vol. 18, No. 2, 2007, pp. 205-217. doi:10.1016/j.foodqual.2005.10.002

[5] C. Tirado and K. Schmidt "WHO Surveillance Programme for Control of Foodborne Infections and Intoxications in Europe. World Health Organization,” Journal of Infection, Vol. 43, No. 1, 2001, pp. 80-84.

[6] E. C. Redmond and C. J. Griffith, "Consumer Food Handling in the Home: A Review of Food Safety Studies," Journal of Food Protection, Vol. 66, No. 1, 2002, pp. 130-161.

[7] M. Bas, A. S. Ersun and G. Kvauc, "Evaluation of Food Hygiene Knowledge, Attitudes and Practices of Food Handlers in Food Businesses in Turkey,” Journal of Food Control, Vol. 17, No. 4, 2006, pp. 317-322. doi:10.1016/j.foodcont.2004.11.006

[8] I. Acheampong, "Food Hygiene of the Cafeteria Facilities of the University of Ghana,” BSc Project Report, Department of Nutrition and Food Science, University of Ghana, Legon, 2005

[9] L. K. King, B. Awumbila, E. A. Canacoo and S. OfosuAmaah, "An Assessment of Safety of Street Foods in the Ga District of Ghana; Implications for Spread of Zoonoses," Acta Tropica, Vol. 76, No. 1, 1998, pp. 39-43. doi:10.1016/S0001-706X(00)00087-5

[10] T. Nuer, "Knowledge, Attitudes and Practices of Fan Milk Product Vendors on Food Hygiene and Food Borne Illness,” BSc Project Report Department of Nutrition and Food Science, University of Ghana, Legon, 2001.

[11] M. Wilson, A. E. Murray, M. A. Black and D. A. McDowell, "The implementation of Hazard Analysis and Critical Control Points In Hospital Catering,” Managing Service Quality, Vol. 7, No. 3, 1997, pp. 150-156. doi:10.1108/09604529710166941

[12] Fung, "Ranges of Microorganisms for Applied Microbiology,” Journal of Food Protection, Vol. 43, 1980, pp. 547-550.

[13] ICMSF, "Microorganisms in Foods 1: Their Significance and Methods of Enumeration" 2nd Edition, Academic Press, New York, 1978, pp. 115-220.

[14] M. JevŠnik, V. Hlebec and P. Raspor, "Food Safety Knowledge and Practices among Food Handlers in Slo- 
venia,” Journal of Food Control, Vol. 19, No. 12, 2007, pp. 1107-1118.

[15] Outagamie County Health and Human Services, Public Health Division, Proper Thawing and Preparation Practices, 2010.

http://www.co.outagamie.wi.us/PublicHealth/Adobe\%20 forms/ThawingandPreparation.pdf

[16] United States Department of Agriculture, Fact Sheets on Safe Food Handling, 2006.

http://www.fsis.usda.gov/FactSheets/Smoking_Meat_and _ Poultry/index.asp

[17] J. Garbutt, "Essentials of Food Microbiology,” Hodder Headline Group, London, 1997, pp. 116-170.

[18] D. J. Bolton, A. Meally, I.S. Blair, D. A. McDowell and C. Cowan, "Food Safety Knowledge of Head Chefs and Catering Managers in Ireland,” Journal of Food Control, Vol. 19, No. 3, 2007, pp. 291-300. doi:10.1016/j.foodcont.2007.04.006

[19] L. Greene, C. Selman, A. Banerjee, R. Marcus, C. Medus and F. J. Angulo, "Food Service Workers' Self-Reported Food Preparation Practices: An EHS-Net Study,” International Journal of Hygiene and Environmental Health, Vol. 208, No. 1-2, 2005, pp. 27-35. doi:10.1016/j.ijheh.2005.01.005

[20] J. G. Black, "Microbiology: Principles and Explorations,"4th Edition, Prentice Hall, Upper Saddle River, 1999, pp. 386-600.

[21] Christchurch city council, "Food Handling Protection and Storage: A Food Safety for Workers Information Source," 1998. http://www.ccc.govt. nz/Health/foods2.asp

[22] I. F. Angelillo, N. M. A. Viggiani, L. Rizzo and A. Bianco, "Food Handlers and Food borne Diseases: Knowledge, Attitudes and Reported Behavior in Italy,” Journal of Food Protection, Vol. 63, No. 30, 2000, pp. 381-385.

[23] P. Mensah, D. Yeboah-Manu, K. Owusu-Darko and A. Ablordey, "Street Foods in Accra, Ghana: How Safe Are They?" Bulletin of the World Health Organization, Vol. 80, No. 7, 2002, pp. 546-554. 